\title{
In situ rumen degradation characteristics and bacterial colonization of whole cottonseed, cottonseed hull and cottonseed meal with different gossypol content
}

\author{
Wei-Kang Wang ${ }^{1}$, Yan-Lu Wang ${ }^{1}$, Wen-Juan Li', Qi-Chao Wu', Kai-Lun Yang ${ }^{2}$, Sheng-Li Li' and \\ Hong-Jian Yang ${ }^{1 *}$ (D)
}

\begin{abstract}
Regarding whole cottonseed (WCS), cottonseed meal (CSM), and cottonseed hull (CSH), in situ rumen incubation was applied to determine their nutrient and gossypol degradation characteristics and bacterial colonization profile in lactating Holstein cows. Nylon bags containing the cotton by-products were incubated for 0, 6, 12, 24, 36, 48 and $72 \mathrm{~h}$ in the rumen, respectively. The relationship between nutrient degradability and free gossypol (FG) content were examined, and the differences in the composition and inferred gene function of the colonized microbiota were studied. As a result, CSM presented highest effective degradability of dry matter, neutral detergent fibre and acid detergent fibre, but the highest effective degradability of crude protein was found in WCS. Free gossypol disappearance rate increased significantly in the first $6 \mathrm{~h}$, and it reached approximately $94 \%$ at $72 \mathrm{~h}$ of incubation among all samples. The level of FG did not affect nutrient degradability of cotton by-products. Significant differences were noted in attached bacterial community structure among cotton by-products after $24 \mathrm{~h}$ rumen incubation. Among the most abundant taxa at genus level, a greater abundance of Cercis gigantea and Succiniclasticum was observed in WCS samples, whereas the CSH and CSM samples contained a greater proportion of Prevotella 1 and Rikenellaceae RC9 gut group. The redundancy analysis revealed that the level of neutral detergent fibre, ether extract, and FG in cotton by-products were significantly positive related with the composition of the attached bacteria. Collectively, our results revealed the dynamics of degradation characteristics, and the difference in the composition of bacterial colonization. These findings are of importance for the targeted improvement of cotton by-products nutrient use efficiency in ruminants and further understanding of the gossypol degradation mechanism in the rumen.
\end{abstract}

Keywords: Attached bacteria, Cotton by-products, Gossypol, In situ degradation

\footnotetext{
*Correspondence: yang_hongjian@sina.com

${ }^{1}$ State Key Laboratory of Animal Nutrition, College of Animal Science and Technology, China Agricultural University, Beijing 100193, China Full list of author information is available at the end of the article
}

\section{Key points}

- FG had no significant effect on nutrient degradability of cotton by-products.

- NDF, EE, and FG content in cotton by-products were significantly related with the composition of the attached microbiota.

- Genes of attached bacteria relating to energy metabolism were more abundant in WCS which presents higher FG content. 


\section{Introduction}

Rumen microbiome is a highly diverse collection of obligate anaerobic microorganisms including fungi, protozoa, bacteria, and archaea (Russell and Rychlik 2001). Particle-associated bacteria account for $70-80 \%$ of rumen microbial matter (Craig et al. 1987), and bacterial attachment is an important instrumental in the process of microbial degradation of dietary plant material (McAllister et al. 1994). Thus, attached bacteria are believed to be the dominant domain, making the greatest contribution to degradation and conversion of feeds in the rumen (Kim et al. 2011). Cotton by-products have been extensively accepted as energy or protein source in diets of ruminant animals though they contain toxic free gossypol (FG), a polyphenolic compound produced by cotton (Gossypium sp.) (Santos et al. 2002), the toxicity of FG is mainly because of its active hydroxyl and aldehyde groups. The main clinical signs of excessive gossypol intake are weakness, apathy, impaired body weight gain, respiratory distress, and even death within a short period in various ruminant animals (Risco et al. 1992; Zelski et al. 1995; Alexander et al. 2008). We believed that the study of attached bacteria on cotton by-products should contribute to the further understanding of gossypol degradation and transformation mechanism in the rumen.

In situ nylon bag technique is a widely adopted procedure to characterize the dynamics of nutrient degradation of feedstuffs in the rumen. Bo et al. (2012) determined the degradation characteristic of cottonseed hulls processed in different ways with in situ rumen incubation. Liu et al. (2016) and Qian et al. (2019) revealed the dynamics of colonization by bacterial communities attached to cottonseed hull and other feeds in the rumen by in situ nylon bag technique. These researches suggesting that the in situ nylon bag technique was a useful method to determine the interaction of rumen microbial diversity and feeds degradation characteristics. Although ruminants in comparison with monogastric animals are believed to have high tolerance to FG toxicity due to microbial fermentation in the rumen, there is no research have been reported on the relationship between the chemical composition and attached bacteria of cotton by-products in the rumen.

In the present study, representative samples of whole cottonseed (WCS), cottonseed meal (CSM) and cottonseed hull $(\mathrm{CSH})$ with different FG content were chosen as experimental materials, and the objective was to determine the effect of FG content on the rumen degradation of cotton by-products as well as the association between chemical composition and solid attached bacteria diversity using an in situ rumen incubation method.

\section{Materials and methods}

\section{Cotton by-products}

Representative cotton by-products were collected from the northern region of Tianshan Mountain in the Xinjiang Uygur Autonomous Region of China for the production of long lint cotton (Gossypium spp.), including three WCS samples, three lint CSH samples and two CSM samples. All samples were dried at $65{ }^{\circ} \mathrm{C}$ for $24 \mathrm{~h}$ in a forced air oven, ground to pass through a $2.00-\mathrm{mm}$ screen, stored prior to chemical analyses and in situ degradation trials.

\section{Animals}

Three mature, rumen-cannulated, lactating Holstein cows (average body weight: $502 \pm 25 \mathrm{~kg}, 151$ days in milk and $36 \mathrm{~kg} /$ day of milk yield at the beginning of the study) were used in this study. Cows were individually housed in three stalls with good ventilation and were fed $25 \mathrm{~kg}$ of dry matter (DM) $(110 \mathrm{~g} / \mathrm{kg}$ of imported Alfalfa, $490 \mathrm{~g} / \mathrm{kg}$ of silage maize, $140 \mathrm{~g} / \mathrm{kg}$ of pressed corn, and $260 \mathrm{~g} / \mathrm{kg}$ of mixture) per animal per day, and free access to drinking water. The cows were fed at 0900 and $1500 \mathrm{~h}$, and milked three times daily. All animal experimental procedures were conducted in accordance with the In stitu-tional Animal Care Committee and animal welfare guidelines of China Agricultural University (CAU20171014-1).

\section{In situ rumen incubation and sampling procedure}

Regarding each cotton by-product sample, approximately $5 \mathrm{~g}$ of the ground samples were weighed into individual in situ nylon bags $(10 \times 20 \mathrm{~cm}$; pore size $=50 \mu \mathrm{m})$, bags containing the samples were introduced into rumen for periods of $0,6,12,24,36,48$ and $72 \mathrm{~h}$. Duplicate bags were incubated in each animal for each incubation time. All bags of each period were placed in the rumen at 0800 $\mathrm{h}$ of the morning simultaneously. Three replications were performed for periods of $0,6,12$ and 24 h of each sample in each animal, and four replications were performed for periods of 36,48 and $72 \mathrm{~h}$.

After removal of all bags containing samples of each incubated time from the rumen, six bags (two bags per sample per cow) were rinsed and manipulated in tap water until the water ran clear, then squeezed by hand to remove excess water and dried at $65^{\circ} \mathrm{C}$ for $24 \mathrm{~h}$ for in situ dry matter disappearance rate analysis, and pool six bags together for nutritional ingredient and FG degradation analysis. The remaining bags of per sample per cow were squeezed by hand to remove loosely attached microbes, pooled and transferred the residue sample to the $2 \mathrm{~mL}$ quick freezing pipe for the future research of solid-attached bacteria. Samples were ground in liquid 
nitrogen quickly, and transported to the laboratory for storage at $-80^{\circ} \mathrm{C}$ until DNA extraction.

\section{Chemical analysis}

For the representative cottonseed by-product samples and the residues used in the trial, DM, crude protein (CP) and ether extract (EE) were determined according to AOAC methods (AOAC 1999), and neutral detergent fibre (NDF) (assayed with sodium sulphite and a heat stable amylase) and acid detergent fibre (ADF) were determined were analysed following the method of Van Soest et al. (1991).

\section{Determination of free gossypol}

Cotton by-products and residual samples in the nylon bags $(0.15 \mathrm{~g})$ in $1.5 \mathrm{~mL}$ acetone were ultrasound $30 \mathrm{~min}$ at $40{ }^{\circ} \mathrm{C}$, centrifuged with the speed of $1000 \times$ g at $25{ }^{\circ} \mathrm{C}$ for $10 \mathrm{~min}$, collected the supernatant, repeat the above processes three times, the extraction were combined and filtrated with $0.45 \mu \mathrm{m}$ microporous, rotary evaporated, dissolved by acetonitrile- $0.2 \%$ phosphoric acid solution and fixed capacity to $2.5 \mathrm{~mL}$.

The content of FG was quantified by high-performance liquid chromatography (HPLC) with a Wufeng analytical instrument (Wufeng Co., Ltd, Shanghai, China) consisting of LC-P100PLUS pump, LC-UV100PULS UV detector and LC-CO100PLUS column heater. The analytical column was a symmetry reversed-phase C18 column $(250 \times 4.6 \mathrm{~mm}, 5 \mu \mathrm{m}, \mathrm{pH}$ $2-8$, Waters, Milford, MA, USA). The mobile phase was $85: 15(\mathrm{v} / \mathrm{v})$ acetonitrile $-0.2 \%$ phosphoric acid solution at a flow rate of $1 \mathrm{~mL} / \mathrm{min}$. Injections were $20 \mu \mathrm{L}$, and the FG was detected at $235 \mathrm{~nm}$.

$100 \mathrm{mg}$ standard gossypol was dissolved into $1 \mathrm{~mL}$ mobile phase, and diluted into 100, 50, 25, 12.5, 6.25, $3.125,1.55,0.78,0.36,0.18,0.09 \mu \mathrm{g} / \mathrm{mL}$ by mobile phase. The standard curve was obtained by linear regression of peak area $\mathrm{Y}$ and gossypol concentration $\mathrm{X}$ under optimal chromatographic conditions as noted above.

\section{Biometric analysis}

The ruminal disappearance (Y) of DM, CP, NDF and ADF at time $(\mathrm{t})$ was fitted to an exponential model by an iterative regression analysis (Ørskov and McDonald 1979) using the GLM procedure of SAS (1999). The model is described by Eq. (1):

$$
\mathrm{Y}=\mathrm{a}+\mathrm{b} \times\left(1-\mathrm{e}^{-\mathrm{c} \times \mathrm{t}}\right)
$$

where ' $\mathrm{e}$ ' is the base of a natural logarithm; the constant "a" represents the soluble and very rapidly degradable component and " $\mathrm{b}$ " represents the insoluble, but potentially degradable component, which has a constant fractional degradation rate (c) per unit time. The effective degradability (ED) of DM, CP, NDF and ADF were then estimated using Eq. (2) (Ørskov and McDonald 1979):

$$
\mathrm{ED}=\mathrm{a}+\frac{\mathrm{b} \times \mathrm{c}}{c+k} .
$$

where ' $\mathrm{k}$ ' refers to the fractional outflow rate. A value of $0.06 / \mathrm{h}$ was assumed for $\mathrm{k}$, as suggested in the literature (INRA 1988).

Collection of solid attached microbiota and DNA extraction The solid attached bacteria were collected according to the method of Larue et al. (2005). Total microbial genomic DNA was extracted using OMEGA Stool DNA Isolation Kit (MoBio Laboratories, Carlsbad, CA) following the manual. The DNA quality and concentration were monitored using NanoDrop 1000 spectrophotometry (Thermo Scientific, Waltham, EUA).

\section{PCR amplification, High throughput sequencing and sequencing data processing}

The V4 hypervariable region of bacterial 16S rRNA gene were amplified with the primers 515F (5'-GTG CCAGCMGCCGCGGTAA-3') and 806R (5'-GGACTA CHVGGGTWTCTAAT-3') (Evans et al. 2014). The PCR was carried out on a Mastercycler Gradient (Eppendorf, Germany) using $25 \mu \mathrm{L}$ reaction volumes, containing $12.5 \mu \mathrm{L} 2 \times$ Taq PCR MasterMix , $3 \mu \mathrm{L}$ BSA $(2 \mathrm{ng} / \mu \mathrm{L})$, 2 Primer $(5 \mathrm{uM}), 2 \mu \mathrm{L}$ template DNA, and $5.5 \mu \mathrm{L} \mathrm{ddH}_{2} \mathrm{O}$. Cycling parameters were $95{ }^{\circ} \mathrm{C}$ for $5 \mathrm{~min}$, followed by 32 cycles of $95{ }^{\circ} \mathrm{C}$ for $45 \mathrm{~s}, 55^{\circ} \mathrm{C}$ for $50 \mathrm{~s}$ and $72{ }^{\circ} \mathrm{C}$ for $45 \mathrm{~s}$ with a final extension at $72{ }^{\circ} \mathrm{C}$ for $10 \mathrm{~min}$. The PCR products were purified using a QIAquick Gel Extraction Kit (QIAGEN, Germany), quantified using Real Time PCR, and sequenced at Allwegene Company, Beijing.

Deep sequencing was performed on Miseq platform at Allwegene Company (Beijing). After the run, image analysis, base calling and error estimation were performed using Illumina Analysis Pipeline Version 2.6. The sequencing data have been submitted into the sequence read archive (SRA) database under accession number PRJNA 702646.

For data analysis, qualified reads were separated using the sample-specific barcode sequences and trimmed with Illumina Analysis Pipeline Version 2.6. And then the dataset were analyzed using usearch (version8.1. The sequences were clustered into operational taxonomic units (OTUs) at a similarity level of $97 \%$ by uparse method (Edgar 2013), to generate rarefaction curves and to calculate the richness and diversity indices. The rdp Classifier tool (Wang et al. 2007) was used 
to representative sequences into different taxonomic groups based on the SILVA ribosomal RNA gene database (Quast et al. 2013). Principal coordinates analysis (PCoA) was used to compare groups of samples based on unweighted Uni-Frac distance metrics (Lozupone and Knight 2005), and an unweighted distance-based analysis of molecular variance (AMOVA) was conducted to assess significant differences among samples using the Mothur v.1.3.0 program (Schloss et al. 2009). The similarity between the microbial communities associated with the cotton by-products were analyzed through a hierarchical cluster analysis using the average-neighbor method. This analysis was conducted using the function hclust in the $\mathrm{R}$ stats package.

\section{Functional gene prediction}

Phylogenetic investigation of communities by reconstruction of unobserved States (PICRUSt) is a bioinformatics tool that uses $16 \mathrm{~S}$ ribosomal DNA sequences to predict the functional gene content of microorganisms (Langille et al. 2013). In the present study, we used PICRUSt to obtain an overview of the genomic and metabolic features represented by the adherent bacterial communities in our samples. We associated OTUs with known bacterial genomes precalculated in PICRUSt, by first picking closed OTUs against the Greengenes $16 \mathrm{~S}$ rRNA gene database (13.5) using QIIME 1.7.0 (Caporaso et al. 2010). The resulting OTU table was then normalized using the script normalize_by_copy_number.py and used for metagenome inference of Kyoto Encyclopedia of Genes and Genomes (KEGG) Orthologs using PICRUSt. The difference in the predicted molecular functions of the bacterial communities attached to the cotton by-products was determined by partial least squares discriminant analysis (PLS-DA) using the SIMCA-P (11.5) software package (Umetrics,Umeå, Sweden).

\section{Statistical analysis}

For comparison between cotton by-products, data for the in situ degradation (animal replicate: $\mathrm{N}=3$ ) was subjected to one way analysis of variance. On detection of overall significant differences by analysis of variance, multiple comparisons among least square means were carried out by Duncan's new multiple range test. The means and standard errors of least square means are reported in the result tables. Significance was declared at $P<0.05$, unless otherwise noted.

We related difference in microbial composition to the chemistry of cottons by-products using redundancy analysis (RDA), as implemented in the Canoco 5.0 software package (Microcomputer Power, Ithaca, NY; Ter Braak and Smilauer 2012). Different chemical composition was introduced as environmental (explanatory) variables. The relative contributions of the top 20 genus-level phylogenetic groups were used as response variables. Redundancy analysis was performed focusing on intersample correlation, and the Monte Carlo Permutation test was applied to decide whether chemical had any statistically significant influence on the microbial composition. Chemical ingredients were considered to have significant effects on microbial composition for $P<0.05$.

\section{Results}

\section{Chemical composition and rumen degradation characteristics of cotton by-products}

According to the results of chemical analysis of cotton by-products (Additional file 1: Table S1), cottonseed meals presented greater amounts of CP, cottonseed hulls presented greater amounts of NDF and ADF, whereas WCS had greater contents of FG and EE.

Highest in situ ruminal ED of DM, NDF, and ADF were found in CSM, whereas WCS had the highest ED of $\mathrm{CP}$. The degradation of FG mainly happened in the first $6 \mathrm{~h}$, and the disappearance rate of FG in WCS and CSH reached over $90 \%$ at $6 \mathrm{~h}$. The maximum disappearance rate of FG among all samples reached over $94 \%$ at $72 \mathrm{~h}$, and it ranked as $\mathrm{WCS}>\mathrm{CSH}>\mathrm{CSM}(P<0.01)$ (Additional file 1: Table S2).

\section{Microbial data of $16 \mathrm{~S}$ rDNA}

In the present study, a $16 \mathrm{~S}$ rDNA gene sequence analysis of samples generated $1,046,756$ sequences with a length greater than $200 \mathrm{bp}$ (Additional file 1: Table S3) and an average of 44,510 \pm 2025 sequences per sample. Quality filtering by QIIME generated 1,046,578 high-quality reads, accounting for $99 \%$ of the raw reads, and an average of 43,607 \pm 2209 sequences per sample. The average sequence length was $291 \mathrm{bp}$.

\section{Diversity of the bacterial microbiota attached to cotton by-products after $24 \mathrm{~h}$ of rumen incubation}

The individually based rarefaction curves for each sample (Additional file 1: Fig. S1). and the Good's coverage which was greater than 0.98 (Additional file 1: Table S3), implying that samples collected at $24 \mathrm{~h}$ of rumen incubation provided sufficient OTU coverage for later analysis of bacterial composition. At the 0.03 dissimilarity level, the OTU numbers, Chao 1, and Shannon indices were significantly affected $(P<0.01)$ by the cotton by-products type as shown in Table 1 . There was no obvious difference of $\alpha$ diversity between CSH and CSM, whereas the OTU numbers, Chao 1 values and Shannon indices of WCS were significantly lower than CSH and CSM. There was a significant negative correlation between $\alpha$ diversity and the content of EE and FG as shown in Table 2. 
Table 1 The a diversity of bacterial community attached to cotton by-products after an incubation of $24 \mathrm{~h}$

\begin{tabular}{llll}
\hline Item $^{\mathbf{a}}$ & OTU $^{\mathbf{b}}$ numbers & Chao 1 values & Shannon index \\
\hline CSH & $1045^{\mathrm{d}}$ & $1233^{\mathrm{d}}$ & $7.5^{\mathrm{d}}$ \\
CSM & $1059^{\mathrm{d}}$ & $1251^{\mathrm{d}}$ & $7.7^{\mathrm{d}}$ \\
WCS & $792^{\mathrm{e}}$ & $1033^{\mathrm{e}}$ & $6.3^{\mathrm{e}}$ \\
SEM & 18.15 & 22.87 & 0.20 \\
$P$-value & $<0.01$ & $<0.01$ & $<0.01$ \\
\hline
\end{tabular}

${ }^{a} \mathrm{CSH}$, cottonseed hull, including 2 samples; CSM, cottonseed meal, including 3 samples; WCS, whole cottonseed, including 3 samples; each kind of sample was incubated in 3 cows simultaneously

${ }^{\mathrm{b}}$ OTU, operational taxonomic units

' SEM, standard error of the difference of the means, $n=3$

d,e Values in a column within the same class without a common superscript are significantly different $(P<0.05)$

Table 2 Pearson correlation coefficients among a diversity of attached bacteria of $24 \mathrm{~h}$ and nutritional composition

\begin{tabular}{llllll}
\hline Item & CP & NDF & ADF & EE & FG \\
\hline OTU numbers & 0.30 & -0.15 & -0.12 & $-0.91^{* *}$ & $-0.85^{* *}$ \\
Chao 1 values & 0.30 & -0.16 & -0.12 & $-0.89^{* *}$ & $-0.85^{* *}$ \\
Shannon index & 0.28 & -0.16 & -0.14 & $-0.69^{* *}$ & $-0.63^{* *}$
\end{tabular}

$A D F$ acid detergent fiber, $C P$ crude protein, $E E$ ether extract, $F G$ free gossypol, $N D F$ neutral detergent fiber, OTU operational taxonomic units ${ }^{* *} P<0.01$

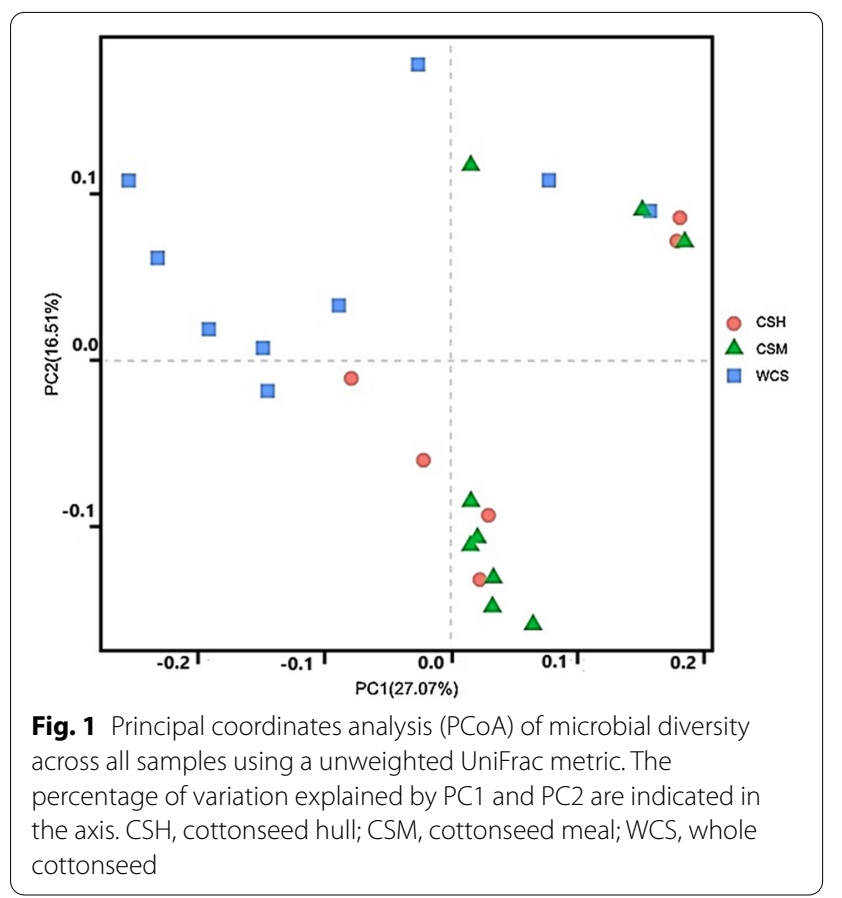

Unweighted UniFrac distance metrics of principal coordinates analysis revealed that the attached bacteria composition varied greatly among different cotton byproducts (AMOVA: F-statistic $=5.12, P<0.01)($ Fig. 1$)$.

Hierarchical cluster analysis of the dendrogram showed that 2 clusters were formed, which revealed differences of microbiota composition among rumen incubated cotton by-products (Additional file 1: Fig. S2). Cluster 1 included 2 distinct subclusters. All CSH and CSM samples fell within cluster 1 . Conversely, cluster 2 comprised samples of WCS. Subclusters were clearly distinguished by cow, subcluster 1 contained all samples from cow $\mathrm{C}$, and subcluster 2 only contained samples from cow A and cow B.

\section{Characterization and comparison of the bacterial communities attached to cotton by-products after $24 \mathrm{~h}$ of rumen incubation}

A total of 21 bacterial phyla were identified among three types of cotton by-products (Additional file 1: Fig. S3). The majority sequences obtained from all cotton byproducts belonging to Bacteroidetes (CSH, 54.8\%, CSM, 58.0\%, WCS, 32.6\%), Firmicutes (CSH, 23.0\% , CSM, 26.5\%, WCS, 38.4\%), Proteobacteria (CSH, 12.4\%, CSM, $2.9 \%$, WCS, $7.2 \%)$, Cyanobacteria (CSH, $0.8 \%$, CSM, $0.1 \%$, WCS, $14.0 \%$ ), Tenericutes (CSH, 2.3\%, CSM, 5.9\%, WCS, 1.5\%), Spirochaetae (CSH, 3.2\%, CSM, 1.8\%, WCS, $1.2 \%)$, and Verrucomicrobia (CSH, 1.2\%, CSM, $1.9 \%$, WCS, $2.1 \%$ ) as shown in Table 3. The other 14 phyla were relatively minor ( $<2 \%$ of total sequences) in abundance in comparison.

At the genus level, 178, 162 and 174 taxa were observed among all WCS, CSH and CSM samples, respectively. For clarity and visualization purposes, the top 20 most abundant taxa are presented in Additional file 1: Fig. S4. The most abundant taxa (those with a relative abundance of $\geq 3 \%$ ) attached to the rumen-incubated cotton by-product samples included Prevotella 1, Cercis gigantea, Rikenellaceae RC9 gut group, Prevotella 7, Erysipelotrichaceae UCG-002, and Succiniclasticum. The WCS present a greater abundance in Cercis gigantea and Succiniclasticum, but Rikenellaceae RC9 gut group and Prevotella 1 were greater in CSH and CSM (Table 3).

\section{Predicted functions of bacteria attached to the cotton by-products after $24 \mathrm{~h}$ of rumen incubation}

The potential functions of attached bacteria were predicted by using PICRUSt, and a total of 37 gene families were found among all samples (Additional file 1: Table S4; Fig. S5). The majority genes of the obtained 37 gene families were belonged to amino acid metabolism (10.05\%), carbohydrate metabolism (10.03\%), membrane transport $(9.60 \%)$, replication and repair $(9.58 \%)$, 
Table 3 Percentage contribution of sequences (\%) evaluated at the phyla and genus level across three-kinds of incubated cotton by-products samples of $24 \mathrm{~h}$

\begin{tabular}{|c|c|c|c|c|c|c|}
\hline Item & & $\mathrm{CSH}$ & CSM & WCS & SEM $^{\mathrm{a}}$ & $P$-value \\
\hline \multicolumn{7}{|l|}{ Phyla } \\
\hline Bacteroidetes & & $54.8^{b}$ & $58.0^{b}$ & $32.6^{c}$ & 2.12 & $<0.01$ \\
\hline Firmicutes & & $23.0^{c}$ & $26.5^{c}$ & $38.4^{\mathrm{b}}$ & 2.94 & 0.03 \\
\hline Proteobacteria & & $12.4^{b}$ & $2.9^{c}$ & $7.2^{b, c}$ & 1.40 & 0.02 \\
\hline Cyanobacteria & & $0.8^{c}$ & $0.1^{c}$ & $14.0^{b}$ & 0.78 & $<0.01$ \\
\hline Tenericutes & & $2.3^{c}$ & $5.9^{b}$ & $1.5^{c}$ & 0.45 & $<0.01$ \\
\hline Spirochaetae & & 3.2 & 1.8 & 1.2 & 0.83 & 0.38 \\
\hline \multirow[t]{2}{*}{ Verrucomicrobia } & & 1.2 & 1.9 & 2.1 & 0.53 & 0.55 \\
\hline & Actinobacteria & 0.3 & 0.5 & 0.8 & 0.15 & 0.20 \\
\hline SR1_Absconditabacteria & & $0.7^{b}$ & $0.6^{b}$ & $0.3^{c}$ & 0.06 & 0.02 \\
\hline Unidentified & & 0.3 & 0.4 & 0.5 & 0.09 & 0.39 \\
\hline Fibrobacteres & & 0.3 & 0.4 & 0.1 & 0.13 & 0.34 \\
\hline Euryarchaeota & & 0.1 & 0.3 & 0.3 & 0.14 & 0.55 \\
\hline Other & & 0.2 & 0.2 & 0.3 & 0.05 & 0.25 \\
\hline \multicolumn{7}{|l|}{ Genus } \\
\hline Prevotellaceae UCG-001 & & $1.2^{b}$ & $1.6^{\mathrm{b}}$ & $0.4^{c}$ & 0.07 & $<0.01$ \\
\hline Ruminococcaceae UCG-014 & & $1.2^{b}$ & $1.5^{\mathrm{b}}$ & $0.4^{c}$ & 0.18 & 0.02 \\
\hline Prevotellaceae UCG-003 & & 1.2 & 1.8 & 0.4 & 0.36 & 0.09 \\
\hline Prevotella 7 & & 2.0 & 3.2 & 1.6 & 0.70 & 0.33 \\
\hline Succinivibrio & & $1.7^{b}$ & $0.6^{c}$ & $0.7^{c}$ & 0.13 & $<0.01$ \\
\hline Ruminobacter & & $1.2^{b}$ & $0.2^{c}$ & $1.0^{\mathrm{b}}$ & 0.14 & 0.01 \\
\hline Selenomonas 1 & & 0.9 & 0.9 & 1.6 & 0.30 & 0.30 \\
\hline Succinivibrionaceae UCG-002 & & $2.7^{b}$ & $0.8^{c}$ & $2.4^{b}$ & 0.21 & $<0.01$ \\
\hline Rikenellaceae RC9 gut group & & $3.6^{c}$ & $6.5^{b}$ & $0.9^{d}$ & 0.52 & $<0.01$ \\
\hline Treponema 2 & & 2.7 & 1.7 & 0.9 & 0.70 & 0.33 \\
\hline Succinivibrionaceae UCG-001 & & $5.4^{b}$ & $0.4^{c}$ & $1.0^{\mathrm{b}, \mathrm{c}}$ & 1.11 & 0.07 \\
\hline Erysipelotrichaceae UCG-002 & & $2.3^{\mathrm{b}, \mathrm{c}}$ & $1.0^{c}$ & $3.8^{\mathrm{b}}$ & 0.54 & 0.03 \\
\hline \multirow[t]{2}{*}{ Succinivibrionaceae UCG-002 } & & $0.3^{c}$ & $0.7^{c}$ & $2.6^{b}$ & 0.47 & 0.04 \\
\hline & Oribacterium & 0.7 & 1.9 & 3.2 & 0.89 & 0.28 \\
\hline Eubacterium coprostanoligenes group & & 0.5 & 0.8 & 2.3 & 0.82 & 0.35 \\
\hline Lachnoclostridium 1 & & 0.1 & 0.9 & 1.8 & 0.63 & 0.31 \\
\hline Cercis gigantea & & $0.7^{c}$ & $0.1^{c}$ & $14.0^{b}$ & 0.79 & $<0.01$ \\
\hline Succiniclasticum & & $2.1^{c}$ & $1.4^{c}$ & $9.3^{b}$ & 1.54 & 0.02 \\
\hline Unidentified & & $23.3^{c}$ & $35.9^{\mathrm{b}}$ & $22.3^{c}$ & 1.40 & $<0.01$ \\
\hline \multirow[t]{2}{*}{ Prevotella 1} & & $29.6^{b}$ & $18.9^{c}$ & $13.7^{c}$ & 1.81 & $<0.01$ \\
\hline & Other & 15.9 & 18.5 & 14.5 & 1.09 & 0.12 \\
\hline
\end{tabular}

CSH cottonseed hull, including 2 samples, CSM cottonseed meal, including 3 samples, WCS whole cottonseed, including 3 samples; each kind of sample was incubated in 3 cows simultaneously

a SEM standard error of the difference of the means, $\mathrm{n}=3$

${ }_{b, c, d}$ Values in a row within the same class without a common superscript are significantly different $(P<0.05)$

energy metabolism (6.71\%), and translation (6.28\%). Of the 6 predominant gene families mentioned earlier, the relative abundances of the genes involved in membrane transport and energy metabolism were significant greater in WCS samples than CSH and CSM, whereas the abundance of genes involved in amino acid metabolism, carbohydrate metabolism, replication and repair, and translation was significant higher in CSH and CSM than WCS $(P<0.01)$. 


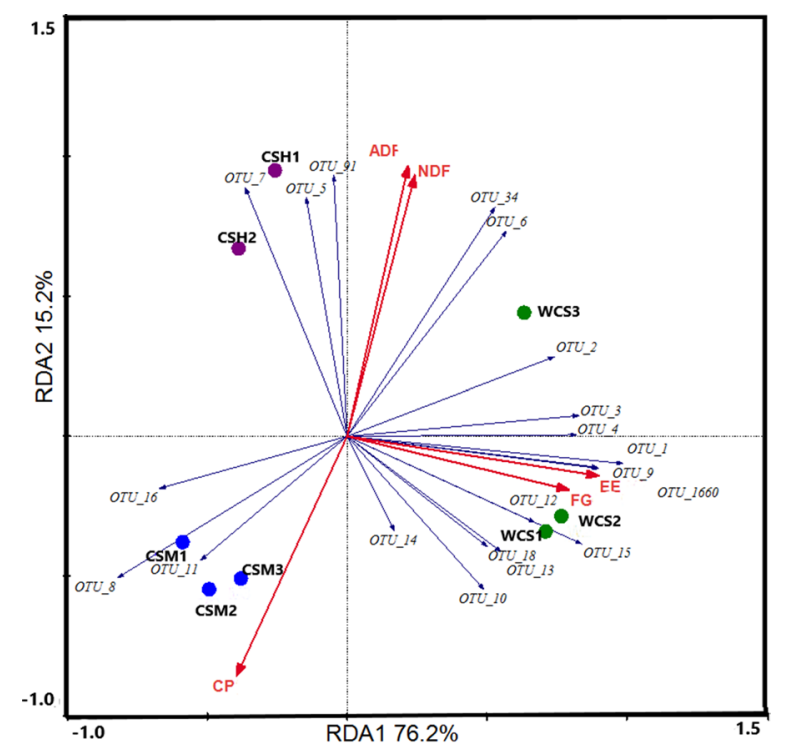

Fig. 2 Biplot of the redundancy analysis (RDA) based on the relative abundance of dominant genera ( $>1 \%$ of total sequence). Constrained explanatory variables are indicated by open triangle arrows. CSH cottonseed hull, CSM cottonseed meal, WCS whole cottonseed, 1-3 sample number of each kind of cotton by-products

\section{Chemical composition coordinated with microbial colonization}

We evaluated the effect of the chemical content on the composition of microbiota colonizing the cotton byproducts by performing a redundancy analysis using NDF, ADF, EE, CP, and FG as constrained explanatory variables and the relative abundances of dominant genera (those with a relative abundance of $\geq 2 \%$ ) as response variables (Fig. 2). Redundancy analysis of the composition of the microbial communities identified the NDF (pseudo-F $=4.4, \mathrm{P}=0.016$ ), ADF (pseudo-F $=2.5, \mathrm{P}=0.076), \mathrm{EE}$ (pseudo- $\mathrm{F}=6.4, \mathrm{P}=0.024), \mathrm{CP}$ (pseudo-F $=1.3, \mathrm{P}=0.352$ ), and $\mathrm{FG}$ (pseudo- $\mathrm{F}=2.6$, $\mathrm{P}=0.036$ ) as significant factors, explaining 76.2 (Axis 1) and $15.2 \%$ (Axis 2), respectively, of the variation in microbial composition. On the redundancy analysis ordination plot, FG content was highly correlated with EE content, and the content of NDF, EE and FG content were closely associated with the composition of attached microbiota. 10 genera, including OUT 1 (Cercis gigantea), OTU 2 (Succiniclasticum), OTU 3 (Erysipelotrichaceae UCG-002), OTU 4 (unclassified Prevotellaceae), OTU 5 (Succinivibrionaceae UCG001), OTU 6 (Succinivibrionaceae UCG-002), OTU 7 (Prevotella 1), OTU 9 (unclassified Bacteroidales S24-7_group), OTU 34 (Ruminobacter), OTU 91 (Prevotella 1), were closely correlated with NDF content. In addition, OTU 1, OTU 2, OTU 3, OTU 4, OTU 6, OTU 9, OTU 10 (Lachnoclostridium 1), OTU 12 (Selenomonas 1), OTU 13 (Lachnospiraceae), OTU 14 (unclassified Verrucomicrobia), OTU 15 (Anaerovibrio), OTU 18 (Oribacterium), OTU 34 (Ruminobacter), OTU 1660 (Succiniclasticum), were closely correlated with EE and FG content.

\section{Discussion}

\section{Chemical composition and rumen degradation characteristics of cotton by-products}

Whole cottonseed, CSH and CSM are important byproducts of cotton production in Xinjiang region of China which were widely used in the diet of dairy cattle. The chemical composition of the studied cotton byproducts agree with feed tables (Azhdari et al. 2012; Du et al. 2016; Judkins et al. 1991). The greater CP and lower fiber contents seen in WCS and CSM compared to CSH may be explained by the shelling process, which might remove cotton-seed kernel protein, and the shelling and prepressing extraction process lead to a significant lower fat content in CSH and CSM. Due to gossypol is a kind of fat-soluble substance, the content of FG in cotton byproducts was closely related with fat content in present study, which was consistent with the result of Gao et al. (2011). The FG content of WCS is mainly affected by varieties, CSM and CSH are by-products obtained from WCS hulling and oil removal, different extraction and pressing methods have different detoxification ability to FG in WCS. Karishma et al. (2016) determined the content range of FG in WCS samples from different sources by HPLC, which varied from 1 to $4 \mathrm{~g} / \mathrm{kg}$. In the present experiment, the content of gossypol in WCS2 and WCS3 was consistent with the above results, but FG in WCS1 was greater than the above results, which may be related to WCS varieties and other factors. Wang et al. (2012) reported that the content of FG in CSM was $0.9 \mathrm{~g} / \mathrm{kg}$, which was greater than the FG content of CSM samples of present study. The FG content of CSH sample in the present experiment was close to the results of Viana et al. (2015).

Cunha et al. (1998) found that DM degradability with $48 \mathrm{~h}$ of incubation time was greater for CSM (62.3\%) followed by broken WCS (57.1\%), CP degradability was also higher for CSM (93.5 \%) followed by broken WCS $(82.5 \%)$, which was consistent with the results of present study. According to the correlation analysis (Fig. 3), NDF and ADF contents in cotton by-products were negatively correlated with the ED of DM $(P<0.01)$, CP content was positively correlated with the ED degradability of DM $(P$ $<0.01$ ), which was consistent with the results of previous study (Kamalak et al. 2005; Kamalak 2006; Mekasha et al. 

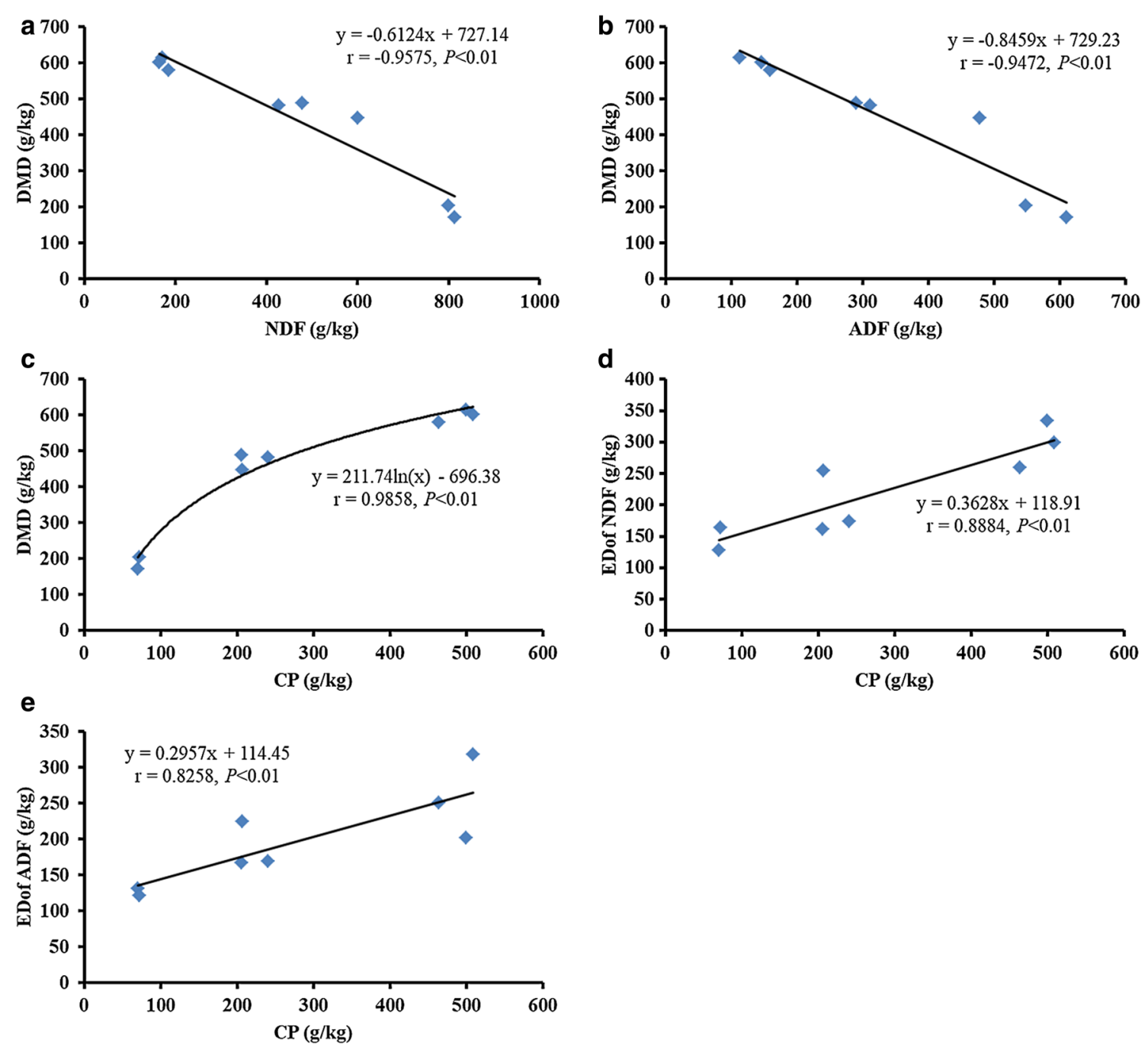

Fig. 3 Correlation analysis of chemical composition and rumen effective degradability of cotton by-products. a correlation analysis of NDF content and $E D$ of $D M, \mathbf{b}$ correlation analysis of ADF content and ED of DM, c correlation analysis of CP content and ED of DM, $\mathbf{d}$ correlation analysis of CP content and $\mathrm{ED}$ of NDF, e correlation analysis of CP content and ED of ADF

2002). Additionally, this experiment also demonstrated that $\mathrm{CP}$ content was positively correlated with the ED of $\mathrm{ADF}$ and $\mathrm{NDF}(P<0.05)$, indicating that there was a promoting effect of $\mathrm{CP}$ on the degradation of crude fiber in the cotton by-products. In present study, the disappearance rate of gossypol approximately reached above $70 \%$ at $0 \mathrm{~h}$, which could be mainly due to the loss caused during the cleaning process of nylon bags. The FG disappearance rate of WCS and CSH reached more than 95\% at $6 \mathrm{~h}$, whereas the disappearance rate of FG in CSM increased relatively slow, which reached more than $93 \%$ at $36 \mathrm{~h}$. The disappearance rate of FG was above $94 \%$ among all samples at $72 \mathrm{~h}$. Generally, the disappearance rate of FG was positive related with its content in cotton
Table 4 Pearson correlation coefficient of FG content and ED of nutrients

\begin{tabular}{lllll}
\hline Item & \multicolumn{1}{l}{ ED } & & & \\
\cline { 2 - 5 } & DM & CP & NDF & ADF \\
\hline FG & 0.07 & 0.53 & -0.41 & -0.23 \\
\hline
\end{tabular}

$A D F$ acid detergent fiber, $C P$ crude protein, $D M$ dry matter, $E D$ effective degradability, FG free gossypol, NDF neutral detergent fiber

by-products. Wang (1995) determined the FG disappearance rate of five WCS samples in an incubation of $24 \mathrm{~h}$ by nylon bag test. It was found that the FG disappearance rate of four WCS samples reached over $80 \%$ at $1 \mathrm{~h}$, and 
all WCS samples reached above $97 \%$ at $24 \mathrm{~h}$, which were consistent with the results of present study.

The relations of FG content and ED of DM, CP, NDF and ADF were determined by correlation analysis (Table 4). The results showed that FG content in cotton by-products presented a poor correlation with the ED of DM, ADF, NDF and CP. We speculated that this could be due to the detoxification of FG by rumen microorganisms, which weakening the detrimental effect of FG on the digestion and metabolism function of rumen microbes.

\section{Microbial colonization of cotton by-products}

Limited information is available on the structure, diversity, and density of attached microbiota of different cotton by-product types. In the present study, results suggesting that cotton by-product types strongly affect the composition and structure of the attached microbiota of rumen incubated samples, as reflected by the clustering of the samples using PCoA and confirmed by AMOVA. We found that more bacteria colonized the CSH and CSM than the WCS, and EE and FG content was significantly negative related with the $\alpha$ diversity of attached bacteria, which could be partly explained by the differing physiochemical conditions of these cotton byproduct types, as well as the antibacterial effect of FG.

Bacteroidetes, Firmicutes, and Proteobacteria were the most abundant phyla among all cotton by-products in present study, which was consistent with the result of previous study (Mao et al. 2015). The phylum Bacteroidetes was the main degraders of non-fibrous carbohydrates in the rumen (Hopper et al. 2001), and it was significantly more abundant in CSH and CSM samples. Generally, there is a negative correlation of fibre content and the abundant of Bacteroidetes. However, the abundant of Bacteroidetes was significant lower in WCS than $\mathrm{CSH}$ which presented greater content of fibre. In addition, there are large amounts of fibrolytic bacteria in the phylum Firmicutes (Evans et al. 2011), and its abundant is positive related with fibre content. However, the phylum Firmicutes was significantly more abundant in WCS than $\mathrm{CSH}$ and CSM samples, which suggesting that the chemical composition of WCS, including greater content of FG, could inhibit the activity of bacteria in Bacteroidetes phylum, and promote the activity of bacteria in Firmicutes phylum. During later research, we had demonstrated that gossypol could inhibit the abundance of Bacteroidetes bacteria and promote the abundance of Firmicutes bacteria by in vitro fermentation using qPCR (Wang et al., 2021).

Among the most abundant taxa at genus level, the present study revealed that the Cercis gigantea and Succiniclasticum abundance was greater in WCS, Prevotella 1 and Rikenellaceae RC9 gut group was greater in CSH and CSM. At the taxonomic level, Cercis gigantea belongs to the phylum of Cyanobacteria. To date, there is no report about Cercis gigantea in the rumen, but Cyanobacteria are common ruminal bacterial phyla and play an important role in nitrate assimilation and reduction of methane production (Prasanna et al. 2002; Flores et al. 2005). Succiniclasticum can convert succinic acid into propionic acid, and degrade starch and cellulose. Prevotella has been reported as the most abundant genus in the rumen of adult dairy cattle, and it is also associated with ruminal carbohydrate and protein fermentation (Wallace et al. 1999; Chiquette et al. 2008). The present study showed that Prevotella spp. dominated in the associated microbiomes of both CSH and CSM, this could explained by the great content of fibre and protein in CSH and CSM, and this finding was consistent with previous report (Stevenson and Weimer 2007). Rikenellaceae is a relatively new bacterial family and therefore its metabolic function in the rumen has not yet been defined. Many researchers found that Rikenellaceae $R C 9$ gut group relative abundance was negatively affected by the oil content in the diet (Zened et al. 2013; Ramos et al. 2018). The lower relative abundance of Rikenellaceae RC9 gut group in WCS may be associated with the greater content of $\mathrm{EE}$.

\section{Predicted functions of the attached bacteria}

With the purpose for further study of the relationship between attached bacteria composition and cotton byproducts degradation, the potential functions of the attached bacteria were determined by using PICRUSt to infer putative metagenomes from the $16 \mathrm{~S}$ rDNA gene profiles. The most abundant functional categories in present study were in agreement with general metabolic functions (such as carbohydrate, protein, and amino acid metabolism) which are essential for the survival of rumen microbiota, and they were also consistent with the observations of previous ruminal metagenomics studies in dairy cows (Parmar et al. 2014; Pitta et al. 2016). Findings of the present study revealed significant differences in bacterial function mainly depending on the chemical composition of cotton by-product samples. Genes relating to energy metabolism were more abundant in the WCS than CSH and CSM, which could be due to the greater content of EE in WCS than CSH and CSM. Yang et al. (2011) found that proteins associated with energy metabolism present a high expression in the detoxification of gossypol by Aspergillus. Niger, which noted that greater abundance of genes relating to energy metabolism in WCS could be also due to its greater content of FG. The great abundance of genes related to carbohydrate and amino acids metabolism in CSH and CSM could be due to their greater content of fibre and protein. 
Collectively, our results revealed that rumen microbiota presented a high ability of gossypol degradation, and there was a poor correlation of gossypol content and the biodegradation of cotton by-products. Diversity, composition, and potential functions of attached bacteria were significantly affected by cotton by-products types, and the difference of ecological community was closely associated with the chemical composition of incubated cotton by-products, especially NDF, EE, and FG content. These findings are of importance for the targeted improvement of cotton by-products nutrient use efficiency in ruminants and the further research of the detoxification mechanism of gossypol by rumen microbes.

\section{Abbreviations}

ADF: Acid detergent fibre; CSH: Cottonseed hull; CSM: Cottonseed meal; CP: Crude protein; DM: Dry matter; EE: Ether extract; ED: Effective degradability; FG: Free gossypol; HPLC: High-performance liquid chromatography; KEGG: Kyoto Encyclopedia of Genes and Genomes; NDF: Neutral detergent fibre; OTU: Operational taxonomic units; PCoA: Principal coordinates analysis; RDA: Redundancy analysis; WCS: Whole cottonseed.

\section{Supplementary Information}

The online version contains supplementary material available at https://doi. org/10.1186/s13568-021-01244-2.

Additional file 1: Table S1. Chemical composition of cotton by-products ( $\mathrm{g} / \mathrm{kg}$ DM). Table S2. Rumen degradability of DM and nutrients of cotton by-products (\%, DM). Table S3. Number of sequences, estimated sample coverage, diversity and OTU richness in each sample. Table S4. Comparisons of the gene pathways of the bacterial microbiota (\% total reads). Fig S1. Summary of rarefaction results based on operational taxonomic unit (OTUs) (3\% divergence) for each sample.A-C,cows; $\mathrm{H}$, cottonseed hull; $\mathrm{M}$, cottonseed meal; W, whole cottonseed;1-3, sample number of each kind of cottonseed by-products. Fig S2. Hierarchical clustering dendrogram representing the OTU table pairwise dissimilarities between the different analyzed samples. OTU, operational taxonomic units; $\mathrm{A}-\mathrm{C}, \mathrm{COws} ; \mathrm{CSH}$, cottonseed hull; CSM, cottonseed meal; WCS, whole cottonseed; 1-3, sample number of each kind of cotton by-products. Fig S3. Percentage contribution of sequences (\%) evaluated at the phylum level across all ruminal-incubated samples.A-C, cows; CSH, cottonseed hull; CSM, cottonseed meal; WCS, whole cottonseed; 1-3, sample number of each kind of cotton by-products. Fig S4. Heatmap analyses of 20 most abundant taxa in all samples. The abundance plot shows the proportion of sequences in each sample. A-C, cows; CSH, cottonseed hull; CSM, cottonseed meal; WCS, whole cottonseed; 1-3, sample number of each kind of cotton by-products. Fig S5. Variations in the KEGG metabolic pathways in the functional bacterial communities across all rumen-incubated samples. CSH, cottonseed hull; CSM, cottonseed meal; WCS, whole cottonseed; 1-3, sample number of each kind of cotton by-products.

\section{Acknowledgements}

Not applicable

\section{Authors' contributions}

WKW, and YLW proposed and organized the overall project. WKW, and YLW performed the majority of the experiments. WJL and QCW gave assistance in lab work and laboratory analyses. WKW wrote the main manuscript text. SLL, KLY, and HJY contributed insightful discussions. All authors reviewed the manuscript.

\section{Availability of data and materials}

Data and materials will be made available on reasonable request. Data from the study are available in NCBI-SRA under accession number PRJNA 702646.

\section{Declarations}

\section{Ethical approval}

All applicable institutional guidelines for the care and use of animals were followed.

\section{Consent for publication}

Not applicable.

\section{Competing interest}

The authors declare that they have no conflict of interest.

\section{Author details}

${ }^{1}$ State Key Laboratory of Animal Nutrition, College of Animal Science and Technology, China Agricultural University, Beijing 100193, China. ${ }^{2}$ College of Animal Sciences, Xinjiang Agricultural University, Urumuqi 830052, China.

Received: 20 May 2021 Accepted: 31 May 2021

Published online: 22 June 2021

\section{References}

Alexander J, Benford D, Cockburn A, Cravedi JP, Dogliotti E, Domenico AD, Fernández-Cruz ML, Fürst P, Fink-Gremmels J, Galli C, Grandjean P, Gzyl $J$ (2008) Scientific opinion gossypol as undesirable substance in animal feed 1 scientific opinion of the panel on contaminants in the food chain. EFSA J 6(9):1-55

AOAC (1999) Official methods of analysis, 16th edn. Association of Analytical Chemists, Washington, DC

Azhdari RE, Salamatdoust R, Lak A (2012) Determination of cottonseed meal degradability with nylon bag technique. Ann Biol Res 3(3):1398-1401

Bo YK, Yang HJ, Wang WX, Liu H, Wang GQ, Yu X (2012) Metabolisable energy, rumen degradation and fermentation characteristics of linted cottonseed hulls, delinted cottonseed hulls and cottonseed linter residue. AsianAustral J Anim Sci 25(2):240-247

Caporaso JG, Kuczynski J, Stombaugh J, Bittinger K, Bushman FD, Costello EK, Fierer N, Pena AG, Goodrich JK, Gordon Jl, Huttley GA, Kelley ST, Knights D, Koenig JE, Ley RE, Lozupone CA, McDonald D, Muegge BD, Pirrung M, Reeder J, Sevinsky JR, Tumbaugh PJ, Walters WA, Widmann J, Yatsunenko T, Zaneveld J, Knight R (2010) QIIME allows analysis of high-throughput community sequencing data. Nat Methods 7:335-336

Chiquette JM, Allison J, Rasmussen MA (2008) Prevotella bryantii 25A used as a probiotic in early-lactation dairy cows: Effect on ruminal fermentation characteristics, milk production, and milk composition. J Dairy Sci 91:3536-3543

Craig WM, Broderick GA, Ricker DB (1987) Quantitation of microorganisms associated with the particulate phase of ruminal ingesta. J Nutr 117:56-62

Cunha JAD, Melotti L, Lucci CDS (1998) Dry matter and protein degradabilities of whole cottonseed and cottonseed meal through nylon bags in situ technique with steers. Braz J Vet Res Anim Sci 35(10):1522-1525

Du S, Xu M, Yao JH (2016) Relationship between fibre degradation kinetics and chemical composition of forages and by-products in ruminants. J Appl Anim Res 44(1):189-193

Edgar RC (2013) UPARSE: highly accurate OTU sequences from microbial amplicon reads. Nat Methods 10(10):996-998

Evans NJ, Brown JM, Murray RD, Getty B, Birtles RJ, Hart CA, Carter SD (2011) Characterization of novel bovine gastrointestinal tract Treponema isolates and comparison with bovine digital dermatitis treponemes. Appl Environ Microb 77(1):138-147

Evans CC, Lepard KJ, Kwak JW, Stancukas MC, Laskowski S, Dougherty J, Moulton L, Glawe A, Wang Y, Leone V, Antonopoulos DA, Smith D, Chang EB, Ciancio MJ (2014) Exercise prevents weight gain and alters the gut microbiota in a mouse model of high fat diet-induced obesity. PLoS ONE 9(3):e92193 
Flores E, Frías JE, Rubio LM, Herrero A (2005) Photosynthetic nitrate assimilation in cyanobacteria. Photosyn Res 83:117-133

Gao XM, Wang AP, Zhang JM, Wang JQ, Zhao QY, Tian KX (2011) Study of nutritional composition and gossypol content of different transgenic cottonseed in china. Acta Agric Boreali-Sin 26(5):126-130

INRA (1988) Alimentation des bovins, ovins et caprins. Institut Nationale de la Recherche Agronomique, Paris

Judkins MB, KrysI L, Barton RK, Holcombe DW, Gunter SA, Broesder JT (1991) Effects of cottonseed meal supplementation time on ruminal fermentation and forage intake by holstein steers fed fescue hay. J Anim Sci 69(9):3789-3797

Kamalak A (2006) Determination of nutritive value of leaves of a native grown shrub, Glycyrrhiza glabra L. using in vitro and in situ measurements. Small Ruminant Res 64:268-278

Kamalak A, Canbolat O, Gurbuz Y, Erol A, Ozay O (2005) Effect of maturity stage on chemical composition, in vitro and in situ dry matter degradation of tumbleweed hay (Gundelia tournefortii L.). Small Ruminant Res 58:149-156

Karishm R (2016) Determination of Total Gossypol and Free Gossypol Content in different varieties of Bt and Non Bt Cotton seed extracts by High- Performance Liquid Chromatography (HPLC). Res J Biotechnol 11(2):70-74

Kim H, Lee I, Kwon Y, Kim BC, Ha S, Lee JH, Kim J (2011) Immobilization of glucose oxidase into polyaniline nanofiber matrix for biofuel cell applications. Biosens Bioelectron 26:3908-3913

Langille MG, Zaneveld J, Caporaso JG, McDonald D, Knights D, Reyes JA, Clemente JC, Burkepile DE, Vega Thurber RL, Knight R, Beiko RG, Huttenhower C (2013) Predictive functional profiling of microbial communities using 16S rRNA marker gene sequences. Nat Biotechnol 31:814-821

Larue R, Yu ZT, Parisi VA, Egan AR, Morrison M (2005) Novel microbial diversity adherent to plant biomass in the herbivore gastrointestinal tract, as revealed by ribosomal intergenic spacer analysis and rrs gene sequencing. Environ Microbi 7(4):530-543

Liu JH, Zhang ML, Xue CX, Zhu WY, Mao SY (2016) Characterization and comparison of the temporal dynamics of ruminal bacterial microbiota colonizing rice straw and alfalfa hay within ruminants. J Dairy Sci 99(12):9668-9681

Lozupone C, Knight R (2005) UniFrac: A new phylogenetic method for comparing microbial communities. Appl Environ Microbiol 71:8228-8235

Mao SY, Zhang ML, Liu JH, Zhu WY (2015) Characterising the bacterial microbiota across the gastrointestinal tracts of dairy cattle: membership and potential function. Sci Rep 5(1):16116

McAllister TA, Bae HD, Jones GA, Cheng KJ (1994) Microbial attachment and feed digestion in the rumen. J Anim Sci 72:3004-3018

Mekasha Y, Tegegne A, Yami A, Umunna NN (2002) Evaluation of non-conventional agro-industrial by-products as supplementary feeds for ruminants: in vitro and metabolism study with sheep. Small Ruminant Res 44:25-35

Ørskov ER, McDonald I (1979) The estimation of protein degradability in the rumen from incubation measurements weighted according to rate of passage. J Agric Sci (camb) 92:499-503

Parmar NR, Solanki JV, Patel AB, Shah TM, Patel AK, Parnerkar S, Kumar JIN, Joshi CG (2014) Metagenome of Mehsani buffalo rumen microbiota: An assessment of variation in feed-dependent phylogenetic and functional classification. J Mol Microbiol Biotechnol 24:249-261

Pitta DW, Indugu N, Kumar S, Vecchiarelli B, Sinha R, Baker LD, Bhukya B, Ferguson JD (2016) Metagenomic assessment of the functional potential of the rumen microbiome in Holstein dairy cows. Anaerobe 38:50-60

Prasanna R, Kumar V, Kumar S, Tripathi AU, Kumar Singh A, Jain MC, Gupta P, Singh PK, Sethunathan N (2002) Methane production in rice soil is inhibited by cyanobacteria. Microbiol Res 157:1-6

Qian WX, Ao WP, Jia CH, Li ZP (2019) Bacterial colonisation of reeds and cottonseed hulls in the rumen of tarim red deer (cervus elaphus yarkandensis). Antonie Van Leeuwenhoek 112(9):1283-1296
Quast C, Pruesse E, Yilmaz P, Gerken J, Schweer T, Yarza P, Peplies J, Glöckner FO (2013) The SILVA ribosomal RNA gene database project: improved data processing and web-based tools. Nucl Acids Res 41(D1):D590-D596

Ramos AFO, Terry SA, Holman DB, Gerhard B, Pereira LGR, André GMS, Alexandre VC (2018) Tucumã oil shifted ruminal fermentation, reducing methane production and altering the microbiome but decreased substrate digestibility within a rusitec fed a mixed hay-concentrate diet. Front Microbiol 9:1647

Risco CA, Holmberg CA, Kutches A (1992) Effect of graded concentrations of gossypol on calf performance: toxicological and pathological considerations. J Dairy Sci 75(10):2787-2798

Russell JB, Rychlik JL (2001) Factors that alter rumen microbial ecology. Science 292:1119-1122

Santos JEP, Villaseňor M, Depeters EJ, Robinson PH, Baldwin BC Jr (2002) Type of cottonseed and level of gossypol in diets of lactating dairy cows: effects on lactation performance and plasma gossypol. J Dairy Sci 85(6):1491-1501

SAS (1999) Statistical analytical system (SAS) users quide: statistics, version 8.2. Statistical Analysis Institute, Cary, NC

Schloss PD, Westcott SL, Ryabin TJ, Hall R, Hartmann M, Hollister EB, Lesniewski RA, Oakley BB, Parks DH, Robinson CJ, Sahl J, Stres WB, Thallinger GG, Van Horn DJ, Weber CF (2009) Introducing mothur: open-source, platformindependent, community-supported software for describing and comparing microbial communities. Appl Environ Microbiol 75:7537-7541

Stevenson DM, Weimer PJ (2007) Dominance of Prevotella and low abundance of classical ruminal bacterial species in the bovine rumen revealed by relative quantification real-time PCR. Appl Microbiol Biotechnol 75:165-174

Van Soest PJ, Robertson JB, Lewis BA (1991) Methods for dietary fiber, neutral fiber, and nonstarch polysaccharides in relation to animal nutrition. J Dairy Sci 74:3583-3597

Viana PG, Lima PMT, Paim T, Souza JR, Dantas AMM, Pereira EF, Goncalves V, Mcmanus C, Abdalla AL, Louvandini H (2015) Gossypol was not detected in the longissimus muscle of lambs fed several forms of cottonseed. Anim Prod Sci 55(6):812-817

Wallace RJ, Atasoglu C, Newbold CJ (1999) Role of peptides in rumen microbial metabolism—Review. Asian-Australas J Anim Sci 12:139-147

Wang YB (1995) Research of detoxification of gossypol by rumen microorganisms. China Agricultural University, China

Wang Q, Garrity GM, Tiedje JM, Cole JR (2007) Naive Bayesian classifier for rapid assignment of rRNA sequences into the new bacterial taxonomy. Appl Environ Microb 73(16):5261-5267

Wang AP, Zhang JM, Meng YL, Deng LQ, LV YF, Li C, Wang JQ (2012) Effects of different sources and levels of dietary gossypol on gossypol residues in plasma and milk of lactating cows. J Dairy Sci 95(9):5127-5132

Wang WK, Wang YL, Li WJ, Wu QC, Li SL, Yang HJ (2021) Gossypol exhibited higher detrimental effect on ruminal fermentation characteristics of lowforage in comparison with high-forage mixed feeds. Toxics 9(3):51

Yang X, Guo JL, Sun JY (2011) Biodegradation of free-gossypol by a new fungus isolated from cotton planted soil. Afr J Microbiol Res 5(19):3066-3072

Zelski RZ, Rothwell JT, Moore RE, Kennedy DJ (1995) Gossypol toxicity in preruminant calves. Aust Vet J 72(10):394-398

Zened A, Combes S, Cauquil L, Mariette J, Klopp C, Bouchez O, Troegeler-Meynadier A, Enjalbert F (2013) Microbial ecology of the rumen evaluated by 454 GS FLX pyrosequencing is affected by starch and oil supplementation of diets. FEMS Microbiol Ecol 83:504-514

\section{Publisher's Note}

Springer Nature remains neutral with regard to jurisdictional claims in published maps and institutional affiliations. 